\title{
Erratum to: Quality of Life and Self-Stigma in Individuals with Schizophrenia
}

\author{
Hui-Ching Wu $\cdot$ I-Chen Tang
}

Published online: 5 May 2012

(C) Springer Science+Business Media, LLC 2012

\section{Erratum to: Psychiatr Q \\ DOI 10.1007/s11126-012-9218-2}

There was an error in the sequence of authorship in the original publication of this article. The correct author sequence is Hui-Ching Wu and I-Chen Tang.

The online version of the original article can be found under doi:10.1007/s11126-012-9218-2.

H.-C. Wu

Department of Social Work, National Taiwan University, 1 Sec. 4, Roosevelt Road, Taipei 10617 , Taiwan

e-mail: hchingwu@ntu.edu.tw

I-C. Tang $(\bowtie)$

School of Medical Sociology and Social Work, Chung Shan Medical University, 110, Sec. 1, Jianguo N. Road, Taichung 402, Taiwan

e-mail: itang@csmu.edu.tw 